\title{
Ecología comunicativa en tiempos del coronavirus SARS-CoV-2. Del moméntum catastróphicum al virtus véritas
}

\section{Communicative ecology in coronavirus SARS-CoV-2 times. From momentun catastrophicum to virus veritas}

Carmen Peñafiel-Saiza, Milagros Ronco-Lópeza , Aitor Castañeda-Zumetaa

a Departamento de Periodismo, Facultad de Ciencias Sociales y de la Comunicación, Universidad del País Vasco, España

\begin{abstract}
Resumen
La pandemia del coronavirus ha puesto en jaque la estabilidad sanitaria e institucional, así como la veracidad de las instituciones y prensa, en la que puede identificarse, paralelamente a la pandemia sanitaria, la infodemia (OMS). El presente artículo dibuja un panorama de la situación mencionada, prestando atención a los principios de ética periodística, la situación informativa española y el trabajo informativo de la Organización Mundial de la Salud. Se parte de una revisión de casos concretos y bibliometría. Se constata la necesidad que tiene la ciudadanía de recibir una información fiable y veraz, trabajando conjuntamente las instituciones públicas y la ciencia empírica a fin de evitar la infodemia, la saturación informativa y las fake news.
\end{abstract}

Palabras clave: Comunicación; Coronavirus; COVID-19; Comunicación de emergencia; fake news; Periodismo; SARS-CoV-2; OMS.

\begin{abstract}
The coronavirus disease has put in check the stability of institutions and health organizations, as well as the veracity of such institutions and press. We can identify pandemic and infodemic (WHO) at the same time. This article pretends to describe the panorama of the aforementioned situation, putting attention to the journalistic principles, the Spanish informative environment, and the informative work of the World Health Organization. We conducted this research using concrete case studies and bibliometrics. We conclude that it is necessary to return to the citizen's need for receiving accurate and verified information. Public institutions and science shall work together to avoid infodemic, informative saturation, and fake news.
\end{abstract}

Keywords: Communication; Coronavirus; COVID-19; Emergency communication; fake news; Journalism; SARS-CoV-2; WHO. 


\section{Introducción}

$\mathrm{D}$ urante el invierno de 2019-2020 el coronavirus SARS-CoV-2, o COVID-19, se ha convertido en el tema de salud más relevante y preocupante a nivel mundial, afectando principalmente a los grupos de edad más avanzada y a aquellas personas con patologías previas. Este virus se ha manifestado con un elevado índice de contagio, lo que ha generado un problema de salud pública en nuestro planeta con un número de casos exponencial que han requerido hospitalización por su situación clínica, vigilancia o aislamiento. Los hospitales se han colapsado y el personal sanitario ha sido el colectivo más expuesto y, a la vez, el que mayor riesgo alberga de contagiar, lo que ha supuesto un elevado estrés para el sistema sanitario.

Todavía sabemos muy poco sobre el comportamiento de este tipo de virus: no sabemos si ha mutado o cómo va a mutar, ni por qué infecta más a los hombres que a las mujeres, ni cuáles son los determinantes que hacen que dos personas de características semejantes desarrollen formas opuestas de la enfermedad (leve o mortal), ni por qué los niños casi nunca tienen formas graves de la infección, ni si los enfermos curados siguen transmitiendo la enfermedad, ni si quedan realmente inmunizados... Hay tantas cuestiones enigmáticas sobre la pandemia, que es difícil adivinar qué sucederá en los próximos meses. Lo que parece evidente, es que esta situación insólita que estamos viviendo cambiará nuestra forma de vida.

Esta pandemia, reconocida así por la Organización Mundial de la Salud (OMS), es muy probable que permanezca entre los virus que habitualmente afectan a la humanidad. Lo que ha quedado demostrado en todos los países, es que los sistemas de salud pública no han sido efectivos para hacerle frente. En muchos casos, como en España, la sanidad pública se ha visto mermada por los recortes sufridos hace unos años por políticas de gobiernos más liberales y la tendencia a la privatización de muchos centros de salud, causando daños muy notables e irreparables.

El coronavirus no es sólo un problema sanitario, sino que tiene otras caras interconectadas de tipo económico, ecológico y social (miedo, sufrimiento y perplejidad) sobre el que debemos reflexionar, porque es una situación sin precedentes. Es la primera pandemia global contra la que se lucha digitalmente, lo que abre un debate sobre los riesgos para la privacidad individual en un sistema de cibervigilancia. Se han creado apps para geolocalizar a personas infectadas con el virus si salen a la calle, y el rastreo de los teléfonos móviles, aunque sea para una buena causa, abre la puerta a la posibilidad de una vigilancia masiva digital para controlar mejor a la sociedad. Como ocurrió con las legislaciones antiterroristas después de los atentados del 11 de septiembre de 2001.

Por otro lado, estamos inmersos en una situación de crisis sanitaria y la ciudadanía necesita recibir la máxima información veraz y completa de las autoridades, para desechar especulaciones y conjeturas gratuitas que pueden crear alarma en la sociedad. Tampoco es conveniente ofrecer falsas soluciones milagrosas para no crear falsas expectativas entre los ciudadanos. Por su parte, los y las profesionales de la información tienen que ser responsables de garantizar el derecho de información mediante noticias veraces, verificadas y contrastadas, que faltan en tantas noticias que nos llegan por medios no oficiales y por las redes sociales. Este derecho de información hará que la ciudadanía tenga un amplio material para recibir críticamente todo lo que le llega en la era digital, marcada por la sobreabundancia informativa. De ahí, la importancia de la labor que deben realizar los medios de comunicación públicos. Todo esto ayuda a contrarrestar las mentiras, bulos y falacias, incluso, en ocasiones, promovidas por algunos sectores políticos.

La comunicación de emergencia como cultura y técnica transversal entre gestores, políticos, facultativos, expertos y periodistas

En tiempos del coronavirus, en el ámbito de la comunicación debemos tener muy presente aspectos tales como: la comunicación de emergencia, la ética y deontología profesional, el derecho a la información, la libertad de expresión, la importancia de las fuentes informativas, la infosaturación, la desinformación o la información malintencionada, así como la importancia y el abuso de las redes sociales. A otro nivel, los medios de comunicación tienen que enfrentarse al miedo y la desconfianza de la ciudadanía, así como al pánico desarrollado por la población civil; no sólo por los casos de infección, sino también por la falta de claridad en la información difundida o por la aplicación de medidas restrictivas poco transparentes.

Desde el 12 de marzo de 2020, entramos en un estado de alarma provocado por el SARS-CoV-2 donde se empezó a organizar una comunicación de emergencia, con una serie de métodos que facilitaban la difusión unidireccional o bidireccional de mensajes a uno o muchos grupos de personas con los detalles de la situación de emergencia. El Gobierno de España comenzó a ofrecer ruedas de prensa con un modelo de preguntas filtradas, que leía el secretario de Estado de Comunicación, Miguel Ángel Oliver. Preguntas que enviaban los periodistas a La Moncloa previamente. Un 
sistema comunicativo muy criticado por distintos sectores profesionales de la información.

Este modelo ha dado paso a la intervención abierta de los periodistas en directo mediante videoconferencia. Un modelo de ruedas de prensa que debiera de haberse puesto en marcha desde el principio para que los ciudadanos estuvieran plenamente informados y pudieran sobrellevar la crisis de la mejor manera posible. En estos casos de alarma o crisis, la mejor comunicación es la que se planifica. La improvisación tiene costos y resultados demasiado frustrantes. Esas actividades requieren, además, de una formación especializada, actitudes y comportamientos abiertos y proactivos. Las habilidades para generar e intercambiar información no son propiedad exclusiva de los expertos en comunicación, sino de un buen trabajo en equipo. No pueden trabajar de forma aislada grupos, sectores, gestores, políticos, sanitarios, expertos, periodistas, etc. Es tanto una cultura como una técnica transversal.

En este escenario, la Federación de Asociaciones de Periodistas de España (FAPE) ha rechazado la posibilidad de controlar o restringir la información y que la única fuente de la misma llegara desde el Gobierno para evitar los bulos sobre el coronavirus, por ser una posibilidad "impropia de un sistema democrático". Nemesio Rodríguez, presidente de la FAPE (16 abril de 2020), ha defendido que en momentos de crisis, "los ciudadanos quieren que los medios difundan información veraz, verificada y contrastada con fuentes fiables. Es decir, aquella información que les permita tomar decisiones con conocimiento de causa". En su opinión, "en lugar de aspirar a controlar la información, los gobiernos tienen que hacer pedagogía: enseñar a los ciudadanos cómo desenmascarar los bulos y alertarles de que puede haber consecuencias penales en la elaboración y difusión de determinados bulos".

\section{Pandemia informativa}

Al inicio del estado de alarma decretada en España desde el 15 de marzo del 2020, la villa de Bilbao publicaba el 3 de abril un folleto elaborado por la Fundación Gizagune, en el que se recomendaba escoger "cosas para leer que no estén relacionadas con la situación de crisis" ( $p$. 3). Dicha elección negativa devenía del aburrimiento provocado por la pandemia que, según la Fundación, incita a leer, escuchar o "ver en la tele sólo noticias que nos preocupan" (Gizagune \& Ayuntamiento de Bilbao, 2020 , p. 3). Cabe señalar que "tele" puede sustituirse perfectamente por "medios de comunicación", en tanto que por las mismas fechas la Facultad de Educación de la
Universidad del País Vasco, también en Bilbao, facilitaba otro folleto a los estudiantes advirtiéndoles de que:

la nueva situación de privación puede generar mucha ansiedad, que muchas veces se agrava por el constante bombardeo y de 'fake news'. Para evitar caer en esta des- o sobre-información, evitaremos estar todo el día pendientes del móvil, Whatsapp, Instagram, Tiktok, la tele y/u otras (Eiguren et. al., 2020, p. 6).

Esto es solo una pequeña muestra de lo que vaticinaba una parte de la comunidad educativa y psicológica: los medios de comunicación y las fake news iban a contribuir al cuadro clínico de la ansiedad provocada por la pandemia del coronavirus. El fenómeno, de alcance internacional, no iba a ser una excepción en España: durante la primera semana de abril, el Ministerio del Interior declaraba haber identificado más de medio centenar de noticias falsas en Internet, amén de 1,5 millones de cuentas destinadas a su difusión (Roldán, 2020). A finales de marzo, la Guardia Civil había habilitado un correo electrónico (ciberestafas@ guardiacivil.org) para que la ciudadanía colaborase en la denuncia de bulos, lo que días después completó la Policía Nacional con una guía de uso donde se ofrecían a los ciudadanos pautas para saber si las noticias eran 0 no falsas. En definitiva: junto con la pandemia vírica, la ciudadanía estaba viviendo fuertes momentos de tensión bajo el azote de noticias que por canales difícilmente controlables le llegaban.

\section{Moméntum catastróphicum}

El periodismo y la transmisión de la información llevan décadas viviendo un momento que bien podría titularse como la obra que Pío Baroja publicó en 1919 para referirse al desastre cultural de la España de su tiempo. Y es que se puede decir sin rodeos que todas las informaciones falsas, sobre todo alimentadas por las redes sociales, son fácilmente disolubles por lo que llamamos "prensa seria", lo que se somete aquí a una discusión mayor: ¿Qué hacer con las apetencias del lector? El problema reside en su criterio, y sobre todo en la dicotomía de hacer elegir al mismo entre la (pseudo) prensa que desea leer, si lo quiere, y lo que en un momento dado se le recomienda que lea. Si vamos a la teoría más moderna del marketing, donde el consumidor es, en palabras de Philip Kotler, el centro de toda actividad de compra-venta, así también quien consume medios tiene derecho a escoger entre a qué otorga credibilidad y a qué no, obviando que no siempre la información que llamamos "oficial" es digna de ser creída. No sobran ejemplos históricos de ello. 


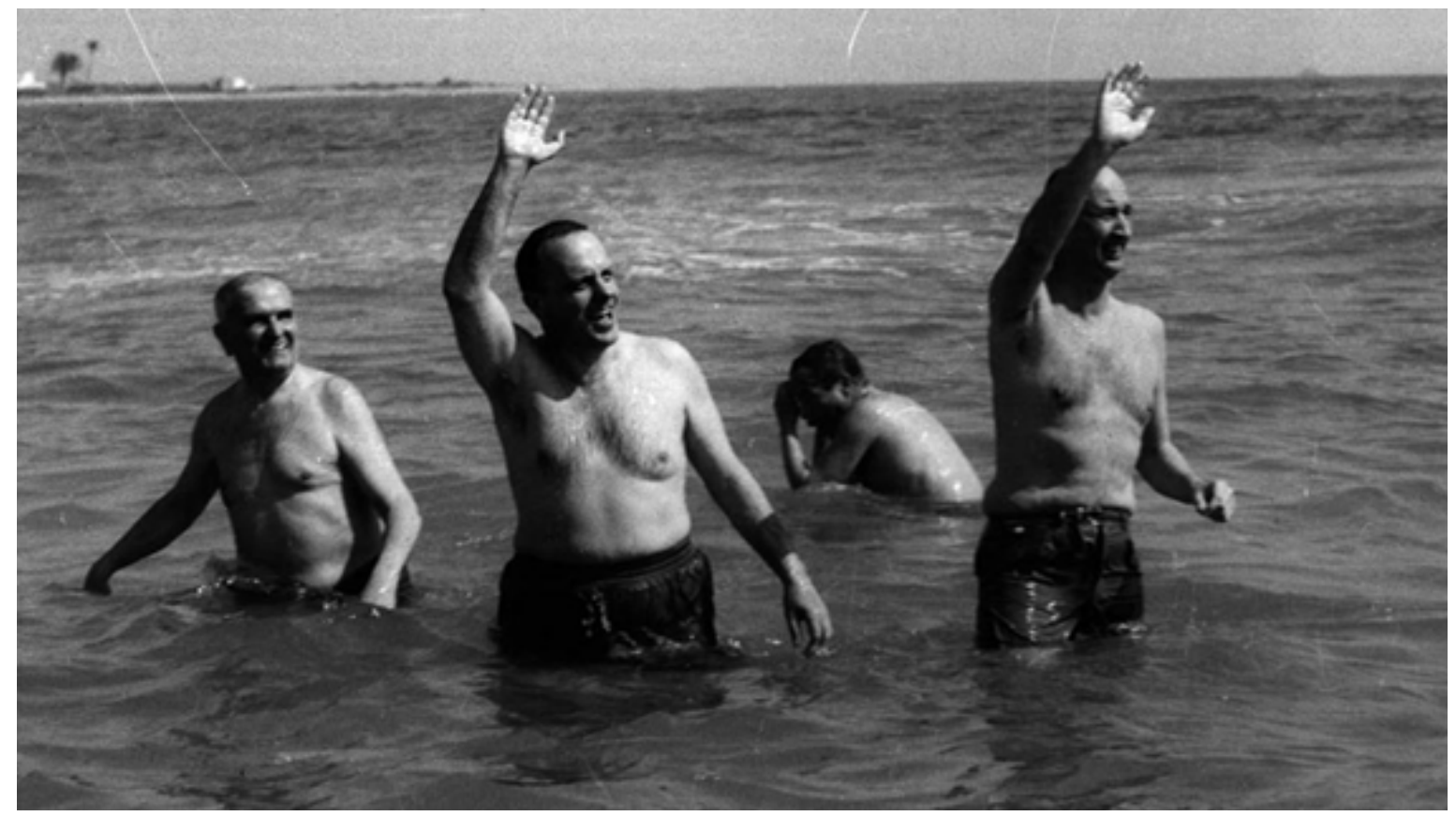

Figura 1. El ex-ministro de gobernación, Manuel Fraga, y su polémica foto en la playa de Palomares (Almería) en 1966. Archivo de La Vanguardia.

No cabe duda de que el periodismo echa mano del marketing para asentar su negocio, en tanto que su sector obviamente necesita recursos para su supervivencia (Iglesias, 2001). Numerosos seminarios ${ }^{1}$ han tratado de responder a si la emisión informativa de un gobierno en crisis es el único canal recomendable para la ciudadanía que desea informarse, o si esa tendencia no discrimina informaciones que al emisor le lleven la contraria. Baste aquí citar la polémica desatada a finales de abril de 2020, cuando la Guardia Civil declaró, por boca de su general José Santiago, que el Cuerpo perseguiría bulos que generaran "desafección a instituciones del Gobierno" (Cuadrado, 2020). El concepto del bulo no serviría aquí para relajar a la cabeza más visible de la oposición española: "Hay que perseguir bulos que provoquen desafección hacia el Gobierno", ordenan a la Guardia Civil. No era un lapsus, quieren perseguir la libertad de expresión y prohibir que les critiquen. No vamos a permitirlo" (Casado, 2020).

Así pues, existe un importante margen de discusión sobre cómo definir al periodismo a día de hoy. Si por tal se entiende la mera facilitación de datos, sin interpretación por parte de quien los prepara, está claro que el siglo XXI no necesita periodismo, más aún si, lejos de informar, desestabiliza la salud del ciudadano. Es así que si la apetencia del consumidor queda por encima de la veracidad, o si por otra parte, los intereses de quien

\footnotetext{
1 Como ejemplo, destacamos el promovido por la Dra. Carmen Beatriz Fernández y Jorge dell'Oro, coordinador de la Organización de Estrategas Políticos de Latinoamérica: “¿La Pandemia puede liquidar la democracia?"
}

financia o compra el medio también lo están -en realidad, no ha habido época en la historia en que no haya sido así-, tampoco necesitamos ya periodismo. El big data y el nuevo espacio cibernético, donde cualquiera puede configurar su propia información a la carta y hacer uso de algoritmos que envían la información que el consumidor quiere, suplen la labor del periódico en papel y digital. Que todo sea cuestión de apetencia e interés, y que lo que venga sea discriminado para que el lector mismo a su criterio consuma lo que quiera y como quiera. Si es verdad o no, vendrá en función de la labor persuasiva del emisor y de aquello a lo que se desee dar crédito. La veracidad morirá en desmedro del business.

Si por contra hablamos de periodismo en su acepción más extendida y elemental, es decir, "actividad profesional que consiste en la obtención, tratamiento, interpretación y difusión de informaciones a través de cualquier medio" (Diccionario de la Real Academia Española), está claro que el periodismo es tarea vigente, aunque tremendamente arriesgada desde el momento en que choca con los intereses que hemos citado. No puede concebirse el periodismo como la actividad de servicio a un solo "señor", con una sola lectura de la realidad como es propio de las dictaduras. Pero tampoco puede bastarle a un lector de criterio que cualquier información que le venga bien -lo que en inglés se llama cherry picking 0 recolección de cerezas- es de por sí veraz e incuestionable. A nuestro modo de ver, existe aún una tarea más importante, propia de la filosofía, que vendría a ser aún más radical: si el periodismo facilita información veraz, ¿qué es la verdad? 


\section{¿Dónde están las fuentes?}

La verdad viene a ser en el periodismo, como en la ciencia, aquello que es demostrable. Un ejemplo, durante la cuarta semana de abril, diversos medios describieron cómo podría ser la salida progresiva de los niños a la calle, cosa que el día 21 desató la furia en redes porque el Gobierno no había decretado lo que gran parte de la ciudadanía había asumido. A pesar de las rectificaciones posteriores, también por falta de apoyos, la ciudadanía había entendido que las cosas se harían como los medios habían dicho, aún sin más pruebas que las hipótesis. No eludimos las responsabilidades comunicativas de las autoridades, aunque un solo párrafo de una información de La Vanguardia, referida a la prórroga del 22 de abril, puede ilustrar mejor lo que decimos:

Antes del día 10 de mayo se pueden tener datos preliminares que ayuden a adoptar nuevas medidas. Lo que sí parece claro es que ya no será un confinamiento estricto y que es muy probable, que se permita salir a pasear y a hacer deporte siempre de manera individual, permitir la apertura de comercios de manera gradual y garantizando la distancia de entre un 1,5 y 2 metros (López, 2020).

Tal como se lee, lo "muy probable" no está más que en la especulación, aun bien formada, de la redactora, y la interpretación a gusto de quien lee, que puede dar un crédito inmediato a una decisión aún no tomada y que de un momento a otro pude variar en gran manera. Este efecto aún más acentuado, cuando el relato periodístico es leído desde el titular, casi única información memorizable para el lector medio. Es una práctica todavía más extendida desde que algunas redes sociales de potente visualidad, como Instagram solo muestran el titular de una noticia hasta que el usuario clica en ella. Así las cosas, se puede decir sin rodeos que, al igual que en ciencia, un artículo periodístico es verdad solo cuando es verificado por fuentes fiables, que es lo primero que se debe atender. Alli donde no existe verificación de fuentes, se abre paso la inventiva, y a más inventiva, un mayor (y lógico) distanciamiento de la realidad, es decir, aquello que es demostrable y atribuible.

Otro ejemplo, como breve pincelada, es el titular del diario más leído de España: el deportivo Marca. Éste publicaba el mismo día 22 de abril la noticia "Desconfinamiento: El Gobierno vasco permitirá salir a correr y andar en bici... pero limitará los paseos" (Velasco, 2020). En ella se hablaba de los planes del gobierno autónomo respecto al diseño del desconfinamiento como si fuese lo que se iba a hacer, obviando que, por entonces, los planes relativos a esta materia solo podían ser propuestos por las regiones, en ningún caso ejecutadas, ya que el ejecutivo nacional se había atribuido esta materia desde la entrada en vigor del estado de alarma, en virtud del artículo 12 de la Orden SND/232/2020:

Todas las autoridades civiles sanitarias de las administraciones públicas del territorio nacional, así como los demás funcionarios y trabajadores al servicio de las mismas, quedarán bajo las órdenes directas del Ministro de Sanidad en cuanto sea necesario para la protección de personas, bienes y lugares, pudiendo imponerles servicios extraordinarios por su duración o por su naturaleza.

Casos como éste evidencian que un lector con no excesiva formación 0 instrucción, puede creerse sin mayor problema que las informaciones que lee son ciertas por el hecho de que las lee, sin reparar en detalles donde, como dice el saber popular, está el demonio.

\section{El baile de las cifras}

Otro ejemplo más que sabido recae en la presentación de datos veraces sobre la realidad, sobre todo cuando son numéricos. A finales de marzo de 2020 nos encontrábamos con portadas de diarios de importante cobertura, ofreciendo las cifras de los fallecimientos por COVID-19 como "peores" que el día anterior. Dado que el pico de la pandemia se alcanzó, según Sanidad, el 2 de abril (950 fallecidos), toda cantidad precedente a aquélla sería siempre peor que la de la jornada anterior, si la predicción de la famosa curva había de producirse. Curiosamente, cifras muy parecidas a las que antes del pico se consideraban "las peores", pasaron a ser leídas como plausibles descensos una vez pasado el 2 de abril.

Pero quizás, el caso más llamativo de errónea lectura de cifras fue el que denunciamos en El Confidencial Digital el día 1 de abril (Castañeda, 2020), donde se contaba el número de contagiados y fallecidos por totales, sin reparar en las poblaciones de aquellos estados. Poco después de marzo, países como Suiza o Bélgica empezaron a emerger, sin perder de vista que si los límites nacionales eran los tenidos en cuenta para calcular qué regiones estaban mejor o peor, los más damnificados eran los microestados (según el texto, San Marino). España dejaba entonces de ser el país donde más muertos y contagiados había junto con China e Italia, a un tercer, cuarto o hasta sexto puesto si las variables se computaban por millones. Las críticas de algunos medios, que siempre han tendido a ofrecer las cifras de muertos antes que los sanados -casi siempre un cuádruple más a nivel (inter)nacional-, aunque curiosamente nunca delante de los contagios, quedaban así disueltas cuando hablaban de España como el que contenía más casos víricos del mundo; en su defecto, con más muertos. 

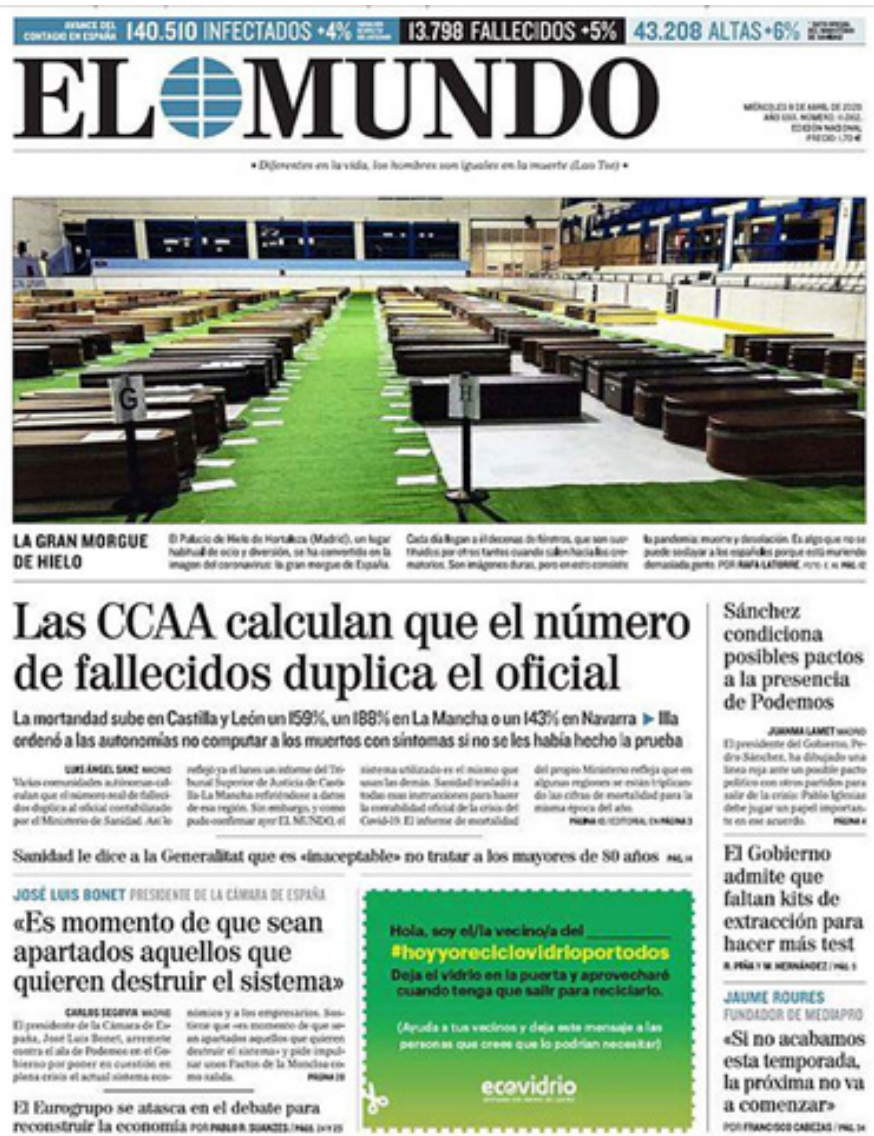

Figura 2. Portada con una fotografía de ataúdes, acompañada de un titular con datos por constatar. El Mundo, 8-4-20.

\section{Vincit omnia véritas}

Dice el psiquiatra español Fernando Sarráis, en su breve guía de 30 Consejos para una vida feliz (2020), que "es una realidad bien constatada que los medios de comunicación y de entretenimiento exponen más sucesos negativos que positivos, porque se piensa que lo malo se vende más que lo bueno" (p. 66). Y añade:

Una posible explicación psicológica de este predominio de lo negativo sobre lo positivo en las noticias y en la mente de las personas se recoge en el dicho: mal de muchos, consuelo de tontos (...). Esta reacción no es lógica, puesto que el hecho de que otros sufran no impide que uno mismo sufra, pero sufrir solo hace sufrir más, porque el sentimiento de soledad supone no ser querido, y el amor es el mejor bálsamo para aliviar el sufrimiento (Sarráis, 2020, pp. 66-67).

Ignoramos, a falta de un estudio más empírico que el que aquí se presenta, qué efectos positivos habrá tenido lo negativo, sobre los positivos por coronavirus. Pero aunque el efecto del que habla Sarráis sea tal, el prestigioso psiquiatra de la Clínica Universitaria de Navarra reitera a lo largo de su obra la tendencia al aprecio de lo verdadero, siendo el periodismo, si quiere existir como tal, abanderado de decir la verdad allí donde es más latente el "todo vale" y el relativismo consumista; donde ya no importa lo que es, sino lo que a cada cual le parece. Debe recuperarse, hoy más que nunca, el lema latino del vincit para el periodismo, y remarcar que si la ciencia médica fuese tan laxa de principios como parte de los medios de comunicación han sido y son, no tendríamos, a poco, más de un mes de pandemia, más de 700.000 recuperados de COVID-19 (Worldometer, 2020) que, gracias a ella, pueden hoy contarlo.

\section{La Organización Mundial de la Salud y la Promoción de la Salud}

Las definiciones de salud son múltiples y han ido cambiando con el tiempo y las circunstancias. No obstante, hay una definición que podemos considerar asentada en nuestra sociedad de forma universal, y es la que, de forma novedosa, emitió la Organización Mundial de la Salud (OMS) en 1946: "La salud es un estado de completo bienestar físico, mental y social, y no solamente la ausencia de afecciones o enfermedades". Ese fue el objetivo que se propusieron cumplir las naciones que formaban parte de la Organización: cubrir la salud desde sus diferentes perspectivas.

La IV Conferencia Internacional, la Conferencia de Yakarta (1997) dio como resultado el documento Promoción de la Salud para el siglo XXI en el que 
refuerzan los elementos que ya habían aparecido en la primera Conferencia Internacional, añadiendo nuevos elementos (p. 6):

Los requisitos para la salud comprenden la paz, la vivienda, la educación, la seguridad social, las relaciones sociales, la alimentación, el ingreso, el empoderamiento de la mujer, un ecosistema estable, el uso sostenible de recursos, la justicia social, el respeto de los derechos humanos y la equidad. Sobre todo, la pobreza es la mayor amenaza para la salud. (...) Las enfermedades infecciosas nuevas y re-emergentes y el mayor reconocimiento de los problemas de salud mental exigen una respuesta urgente. Es indispensable que la promoción de la salud evolucione para adaptarse a los cambios en los factores determinantes de la salud.

\section{Coordinación de la OMS en epidemias y pandemias}

Bajo la coordinación de la OMS, en 1951 los Estados Miembros de la OMS aprobaron el primer Reglamento Sanitario Internacional (RSI). En 2005 se aprobó el actual $\mathrm{RSI}$, que entró en vigor en $2007^{2}$, mediante el que los países acordaron evaluar y notificar todo lo referente a salud pública. Su finalidad es "prevenir la propagación internacional de enfermedades, proteger contra esa propagación, controlarla y darle una respuesta de salud pública proporcionada y restringida a los riesgos para la salud pública y evitando al mismo tiempo las interferencias innecesarias con el tráfico y el comercio internacionales" (RSI, 2005, Prefacio, 8).

El RSI supuso un cambio importante al plantear que el control de las emergencias y los riesgos para la salud pública se realizaran en cada país, y no en el control de fronteras, como se hizo en un principio, así como ampliar su alcance a "toda situación o suceso que potencialmente entrañe un riesgo para la salud pública, ya sea de naturaleza biológica, radionuclear, o química" frente a las seis enfermedades del supuesto inicial ${ }^{3}$.

En las operaciones de alerta y respuesta rápida, el $\mathrm{RSI}$ proporciona un marco para las actividades de la OMS ante epidemias, que se llevan a cabo en colaboración con los países para controlar los brotes internacionales y reforzar la seguridad. En este sentido, la OMS cuenta con el Centro Estratégico de Operaciones Sanitarias (SHOC) y la Red Mundial de Alerta y Respuesta ante Brotes Epidémicos (GOARN).

EI SHOC es el observatorio de la respuesta mundial de

2 Entre 1951 y 2005 se aprobó una segunda edición del RSI en 1969, que se modificó ligeramente en 1973 y 1981.

3 Cólera, peste, fiebre amarilla, viruela, fiebre recurrente y tifus. No obstante, a partir de 1969 solo las tres primeras se mantuvieron como de notificación obligatoria (OMS, 1965). la OMS a las epidemias, un punto único de coordinación para la respuesta a las crisis sanitarias, en particular los brotes de enfermedades infecciosas, los desastres naturales y las emergencias químicas. Por ejemplo, en 2005 coordinó la respuesta médica internacional al huracán Katrina y a los terremotos que sufrió el Pakistán. Participa además en las actividades de preparación mundial para la consideración de pandemias y ofrece asesoramiento técnico a las Oficinas Regionales de la OMS además de a otros organismos.

La GOARN es una red de colaboración técnica entre instituciones y redes que unen sus recursos humanos y técnicos para identificar y responder rápidamente a posibles brotes epidémicos con el propósito de mantener a la comunidad internacional continuamente alerta ante las amenazas. Sus objetivos son: combatir la propagación internacional de brotes epidémicos, velar por que llegue rápidamente a los países afectados la asistencia técnica apropiada, y contribuir a la preparación para epidemias y el aumento de la capacidad a largo plazo. Esta Red de Alerta elabora los principios rectores y los protocolos operacionales, con el fin de normalizar los sistemas epidemiológicos y de laboratorio, de gestión clínica, de investigación, de comunicaciones, de apoyo logístico, de seguridad y de evacuación y comunicaciones.

\section{Emergencias globales en el siglo XXI}

El 30 de enero de 2020, la OMS calificó la epidemia de COVID-19 como Emergencia de Salud Pública de Interés Internacional (ESPII), cuando el informe de situación señalaba su presencia en 19 países del mundo. Es la sexta vez que la OMS declara una ESPII desde la entrada en vigor del RSI en 2005. El 11 de marzo, la OMS determinó en su evaluación que el COVID-19 podía caracterizarse como una pandemia ${ }^{4}$. La caracterización de pandemia significa que la epidemia se ha extendido por varios países, continentes o todo el mundo, y que afecta a un gran número de personas.

El Director General de la OMS declaró:

Nunca antes habíamos visto una pandemia provocada por un coronavirus. Y nunca antes hemos visto una pandemia que pueda ser controlada, al mismo tiempo (...) Nuestro mensaje sigue siendo que deben adoptar un enfoque integral. No sólo realizar pruebas de detección. No sólo el rastreo de contactos. No sólo la cuarentena. No sólo el distanciamiento social. Háganlo todo.

A su vez, desde la entrada en funcionamiento del RSI en 2005, la OMS ha declarado las siguientes ESPII: la

\footnotetext{
4 "Se llama pandemia a la propagación mundial de una nueva enfermedad" (OMS, 24 de febrero de 2010).
} 
gripe A (H1N1) de 2009, el poliovirus salvaje de 2014, el virus Ébola en África Occidental en 2014, el virus del Zika de 2016, el virus Ébola en la República del Congo en 2019 y el coronavirus SARS-CoV-2 en 2020. De ellas, dos han sido declaradas pandemias: La gripe A (H1N1) pdm09 y el SARS-CoV-2; ambas, provocadas por virus nuevos y desconocidos.

El nuevo tipo de virus Influenza A (H1N1) se localizó por primera vez en Estados Unidos y en México, y se propagó rápidamente. No están muy claras las cifras de afectados y fallecidos. Para la OMS, que a día de hoy no ha publicado otras cifras, causó la muerte de alrededor de 18.500 personas en 213 países $^{5}$. En ese caso, los niños fueron uno de los grupos más afectados, a diferencia de las personas mayores de 65 años, menos vulnerables; la mayoría de los casos fueron considerados "leves" Por primera vez, según destaca la OMS, se desarrolló una vacuna y se puso a disposición de múltiples países durante el primer año de la pandemia. Actualmente, es un virus de la gripe humana habitual y continúa circulando de forma estacional alrededor del mundo. Respecto al coronavirus SARS-CoV-2, las cifras de afectados son muy superiores y la pandemia sigue su curso.

\section{La importancia de la información a lo largo de las crisis}

Una de las principales conclusiones que se establecieron al dar por finalizada la pandemia de Influenza H1N1, fue la mala cobertura informativa que había existido por parte de la OMS, la falta de transparencia informativa. Un documento publicado el pasado año por la plataforma Ciencias Sociales en Acción Humanitaria, promovida por UNICEF y el Instituto de Estudios para el Desarrollo, recoge algunas "lecciones aprendidas de epidemias anteriores" como es el caso de la transparencia informativa, destacando que retener información al público puede ser contraproducente. Si el público no obtiene la información a través de las fuentes oficiales, lo van a hacer a través de medios que pueden no ser fiables. En este documento se recomienda a las autoridades ser transparentes sobre lo que se sabe de la epidemia, y también que se recurra a los expertos en comunicación (p. 3s):

La aceptación de las recomendaciones de prevención de riesgos ha sido mayor cuando los mensajes fueron entregados por intermediarios confiables (...) Pueden ser líderes comunitarios, personas de confianza en los medios de comunicación. [Se debe] Construir relaciones y fuentes confiables con los medios; asegurar mensajes consistentes y actualizados; sea transparente sobre los errores de

5 Conclusiones de la OMS al dar por finalizada la pandemia en agosto de 2010. V. OPS (10 de agosto de 2020). informes anteriores. Los mensajes sobre la enfermedad y los métodos de prevención deben enmarcarse dentro del punto de vista y el lenguaje de las comunidades afectadas, y a través de intermediarios confiables (...) Cuando las comunidades se han involucrado y están bien informadas, han mostrado su disposición a asumir un papel de liderazgo en las medidas preventivas y cumplir voluntariamente.

En la rueda de prensa de 6 de marzo sobre el COVID-19, el Director General de la OMS indicaba: "este es el momento de los hechos, no del miedo; de la ciencia, no de los rumores; y de la solidaridad, no de la estigmatización".

Se le ha dado la vuelta a la situación vivida en la anterior crisis mundial; en la actual pandemia por coronavirus, parece que nos encontramos con un exceso de información. En palabras de la OMS, de infodemia. Desde el principio, la Organización ha implementado una página web con orientaciones al público y con información actualizada, ha publicado informes diarios de situación desde el 21 de enero de 2020 hasta la actualidad, mantiene la actividad informativa en Twitter ${ }^{6}$, emite periódicamente comunicados y conferencias de prensa, ofrece información sobre la respuesta de la OMS en los distintos países. También ofrece consejos sobre diversos temas relacionados con la pandemia a través de diversas Guías?:

- Recomendaciones para el diagnóstico de laboratorio de TB durante la pandemia de COVID-19.

- Recomendaciones para ampliar el acceso para el lavado de manos y su uso apropiado.

- El programa de inmunización en el contexto de la pandemia de COVID-19.

- COVID-19. Fases de desarrollo de una vacuna.

- Consideraciones sobre ajustes medidas de distanciamiento social y las medidas relacionadas con los viajes.

- El uso de túneles y otras tecnologías para la desinfección de humanos utilizando rociado de productos químicos o luz UV-C.

- Cómo abordar la salud mental y los aspectos psicosociales del brote de COVID-19.

A su vez, se tienen en cuenta diversos temas relacionados todos ellos con la situación de pandemia provocada por el coronavirus, y que la OMS va recogiendo en publicaciones a través de su página web como Materiales Clave: Salud Mental y COVID-19,

\footnotetext{
$\overline{6}$ Ver la cuenta de Twitter del Dr. Tedros Ghebreyesus, director de la OMS (https://twitter.com/DrTedros) y la cuenta de la propia Organización (https:// twitter.com/who).

7 Todas ellas recuperables en https://www.paho.org/es/guias (5-6-2020).
} 
Tabaco y COVID-19, Sida y COVID-19, Estrategia de Vigilancia para la infección humana por COVID-19, Medidas de Salud Pública por COVID-19 relacionadas con la escuela, COVID-19 en prisiones y otros centros de detención, Salud Pública y Medidas Sociales en el lugar de trabajo, Lactancia materna durante el COVID-19, etc.

Por lo que se refiere a los medios de comunicación, la OMS ha elaborado dos guías: "COVID-19 Glosario sobre brotes y epidemias. Un recurso para periodistas y comunicadores" y "COVID-19 Consejos para informar. Guía para periodistas". La primera es, como su nombre indica, un Glosario que se considera útil para desempeñar la labor informativa de periodistas y comunicadores sobre términos técnicos utilizados durante brotes y epidemias. La segunda ofrece herramientas:

Para que los periodistas puedan realizar una cobertura responsable de la pandemia del COVID-19 y brindar información basada en la evidencia. También se proponen enfoques para la cobertura y se incentiva a que el periodismo aporte consejos y soluciones que contribuyan a reducir los riesgos para la salud y salvar vidas" (Organización Mundial de la Salud, 2020c).

Por último, recientemente se han incorporado dos aplicaciones para móvil con el objetivo de mantener informada a la población y a los profesionales de la salud en cualquier circunstancia: La aplicación WHO Academy, concebida para prestar apoyo a los profesionales de la salud durante el COVID-19, y la aplicación WHO Info, para informar al público en general, que ofrecerá "las últimas iniciativas y alianzas de la OMS, así como información actualizada sobre la carrera para encontrar medicamentos y vacunas contra la enfermedad. El número de casos de COVID-19, organizados por país y cronológicamente, se actualizan continuamente en la aplicación a partir de los flujos de datos oficiales de la OMS sobre la COVID-19".

La OMS especifica que las aplicaciones están disponibles para descarga gratuita tanto en Apple App Store como en Google Play Store en árabe, chino, español, francés, inglés y ruso.

\section{Discusión y conclusión}

Sostenemos que la actual época de emergencia sanitaria ha puesto de relieve la importancia de disponer de unos servicios públicos suficientes, universales y de calidad en todos los ámbitos fundamentales de la vida humana. Empezando por una red de salud pública dotada con recursos suficientes y de profesionales facultativos bien tratados. Esta realidad también se debe dar en otros sectores como la educación, la atención social y la atención a las personas mayores, sectores de la población que deben ser tratados con calidad y dignidad.

Es evidente que muchas cosas cambiarán a nivel mundial después de esta pandemia. Se habla de la ineficacia del modelo neoliberal, de la necesidad de situar las prioridades sociales, del impacto del cambio climático y de la reducción de la biodiversidad, de establecer una mejor relación con el entorno y el planeta, etc. Todo ello afectará desde un punto de vista social, económico, científico y tecnológico bajo una polarización social inevitable. Lo cierto es que toda esta acumulación de experiencias nos debiera invitar a buscar y desarrollar una sociedad más justa y sostenible.

Parece claro que estamos entrando dentro de un nuevo orden mundial, en el que deberemos ser capaces de repensar un mundo mejor y lograr una transformación comprometida con la justicia social.

Por otra parte, defendemos que los medios de comunicación han jugado un papel predominante en la información de la ciudadanía. En la época de la pandemia el consumo de noticias ha crecido extraordinariamente y se ha convertido en un recurso valioso para las personas, incluso para muchos jóvenes que estaban alejados del mundo de la información y de los medios tradicionales. La información es un bien imprescindible y necesario en situaciones de emergencia, no sólo es importante para la transformación de los medios de comunicación sino también para la democracia. En esta época de emergencia sanitaria han resurgido los medios tradicionales y especialmente la televisión. Los datos del contexto europeo también demuestran el fuerte incremento del consumo de noticias por parte de los jóvenes que ha crecido un $20 \%$ durante el inicio del COVID-19. En España, el consumo de televisión de esta franja de edad ante la emergencia sanitaria ha sido del $59,6 \%$ y el de prensa digital del $72 \%$ (Casero, 2020, p. 7).

Durante meses, los principales medios de todo el planeta nos han hablado de un único tema: el coronavirus. El estado de alarma en España ha invitado al periodismo a realizar una apuesta decidida por la libertad de prensa y por la información veraz e independiente en tiempos muy difíciles. Los profesionales de la información han realizado un gran esfuerzo para que las noticias lleguen con la mejor praxis y ética a toda la ciudadanía, conscientes del valor que supone el ejercicio del periodismo, calificando como "esencial" el derecho a la información como un bien público de toda democracia. En este escenario de alarma los y las profesionales del periodismo luchan contra la desinformación que lideran grupos organizados en plataformas de diferentes redes sociales, en muchos casos desde los extremos de la política. La OMS ha 
definido este fenómeno como infodemia, pandemia de info-falsedades y los sistemas de mensajería móvil se han convertido en verdaderas fábricas de fakes news difundiendo exponencialmente bulos y engaños.

La crisis de COVID-19 es una crisis de salud pública, una crisis económica y, evidentemente, una crisis de información. Junto a la crisis de salud primaria, esta pandemia ha sido reconocida como un gran problema por la avalancha de información de todo tipo y a través de todo tipo de canales. La desinformación provocada por las fake news hasta cotas nunca vistas, así como los bajos niveles de alfabetización en salud por parte de la sociedad, suponen dos de los problemas más graves. En su esfuerzo por minimizarlos, la OMS se ha volcado en la publicación de documentos de divulgación científica adaptados al público no especializado, así como documentos para formación y utilización de los comunicadores. La necesidad de comunicar bien, con información médica precisa, confiable y comprensible, nunca ha sido tan urgente y necesaria.

\section{Financiación}

La primera autora es investigadora Principal del Grupo Consolidado GIU 17/010 e Investigadora Principal del Proyecto sobre Slow Journalism financiado por el MINECO, Ref: CSO 2016-76020-R (AEI/FEDER, UE)

\section{Referencias Bibliográficas}

Adhanom Ghebreyesus, T. (2020, 11 de marzo). Alocución de apertura del director General de la OMS en la rueda de prensa sobre la COVID-19. Recuperado de https://www.who.int/es/dg/speeches/ detail/who-director-general-s-opening-remarks-atthe-media-briefing-on-covid-19---11-march-2020

Adhanom Ghebreyesus, T. (2020, 6 de marzo). Alocución de apertura del Director General de la OMS en la rueda de prensa sobre la COVID-19. Recuperado de https://www.who.int/es/dg/speeches/ detail/who-director-general-s-opening-remarks-atthe-media-briefing-on-covid-19---6-march-2020

Beatriz-Fernández, C. (Present.) (20202, 10 de abril). ¿La Pandemia puede liquidar la democracia? [Tertulia web] Cibertertulia Pandemia y Democracia. Portal elecciones.net. El Portal político iberoamericano. Recuperado de http://www.e-lecciones.net/sed/ opinion/id/1344/?show=2

Casado, P. [pablocasado]. (2020, 22 de abril). "No podemos aceptar que haya mensajes negativos», dice una ministra. "Hay que perseguir bulos que provoquen desafección hacia el Gobierno», ordenan a la Guardia Civil. No era un lapsus, quieren perseguir la libertad de expresión y prohibir que les critiquen. No vamos a permitirlo. [Tuit]. Recuperado de www.twitter.com/ pablocasado_/status/1252628404546961409

Casero-Ripollés, A. (2020). Impact of COVID-19 on the media system. Communicative and democratic consequences of news consumption during the Outbreak. El Profesional de la Información, 29(2), 1-11. doi: 10.3145/epi.2020.mar.23

Castañeda, A. (2020, 1 de abril). Cifras, periodismo y crisis. El Confidencial Digital. [Artículo de opinión]. Recuperado de www.elconfidencialdigital. com/articulo/la_voz_del_lector/cifras-periodismocrisis/20200401113950141921.html

Cuadrado, J. M. (21 de abril de 2020). La Guardia Civil pide informes de bulos que puedan generar desafección a instituciones del Gobierno. El País. [Noticia]. Recuperado de www.elpais.com/espana/2020-04-20/ la-guardia-civil-pide-informes-de-bulos-que-puedangenerar-desafeccion-a-instituciones-del-gobierno. html

Eiguren, A., Berasategi, N., Ozamiz, N., Monge, N., Pikaza, M., Dosil, M., \& Idoiaga, N. (2020). Recomendaciones sociales, psicológicas, físicas y académicas para el alumnado universitario. Bilbao, España: Facultad de Educación de la Universidad del País Vasco. [Folleto]

Guardia Civil (Ministerio del Interior). (2020, 22 de abril). La Guardia Civil crea un canal de comunicación ciudadana para recibir información sobre fraudes $y$ estafas online con ocasión del coronavirus. [Nota de Prensa]. Recuperado de www.interior.gob.es/prensa/noticias/asset_publisher/ GHU8Ap6ztgsg/content/id/11650383

Fundación Gizagune y Ayuntamiento de Bilbao (2020). Convivencia en tiempos de Alarma Sanitaria. [Web]. Recuperado de https://www.bilbao.eus/cs/ Satellite?c=BIO_Noticia_FA\&cid=1279197397145\&I anguage $=$ es $\&$ pageid $=3000075248$ pagename $=$ Bilb aonet\%2FBIO_Noticia_FA\%2FBIO_Noticia

Iglesias, F. (2002). Marketing periodístico. Barcelona, España: Ariel

López, C. (2020, 22 de abril). El estado de alarma se tendrá que prolongar los largos meses que dure 
la fase de desconfinamiento. La Vanguardia. [Reportaje]. Recuperado de www.lavanguardia. com/vida/20200422/48677874203/estado-alarmadesconfinamiento-fase.html

Ministerio de Sanidad. (2020). Enfermedad por nuevo coronavirus, COVID-19: Información actualizada [Web]. Recuperado de www.mscbs. gob.es/en/profesionales/saludPublica/ccayes/ alertasActual/nCov-China/home.htm

Organización Mundial de la Salud. (2020a). [Sitio web] Recuperado de https://www.who.int/es/emergencies/ diseases/novel-coronavirus-2019

Organización Mundial de la Salud. (2020b). COVID-19 Glosario sobre brotes y epidemias. Un recurso para periodistas y comunicadores. [web]. Recuperado de https://www.paho.org/es/node/70518

Organización Mundial de la Salud. (2020c). COVID-19 Consejos para informar. Guía para periodistas. [web]. Recuperado de https://www.paho.org/es/ documentos/covid-19-consejos-para-informar-guiapara-periodistas

Organización Mundial de la Salud. (2006). Constitución de la OMS. Documentos básicos. Suplemento de la $45^{a}$ edición. Recuperado de https://www.who. int/governance/eb/who_constitution_en.pdf

Organización Mundial de la Salud. (2005). Reglamento Sanitario Internacional. Ed. 2016. Recuperado de https://apps.who.int/iris/bitstream/ handle/10665/246186/9789243580494-spa. pdf?sequence $=1$

Organización Mundial de la Salud. (2005). Reglamento Sanitario Internacional. Operaciones de alerta y respuesta. Recuperado de https://www.who.int/csr/ alertresponse/es/

Organización Mundial de la Salud. (1997). Declaración de Yakarta. Promoción de la salud del siglo XXI. Recuperado de https://www.who.int/healthpromotion/ conferences/previous/jakarta/en/hpr_jakarta_ declaration_sp.pdf

Platform Social Science in Humanitarian Action (UNICEF and the Institute of Development Studies) (2019). Social science lessons learned from Influenza and SARS. The Social Science in Humanitarian Action: A Communication for Development Platform is a partnership between UNICEF and the Institute of Development Studies (IDS) and support from Anthrologica. Recuperado de https://opendocs.ids.ac.uk/opendocs/bitstream/ handle/20.500.12413/14326/Evidence_Summary_ Social_Science_Lessons_Influenza_SARS. pdf?sequence $=3 \&$ isAllowed $=y$

Policía Nacional (Ministerio del Interior). La Policía Nacional presenta la primera guía para evitar ser manipulados por las fake news. [Nota de Prensa] Recuperado el día 22 de abril de 2020 de www. interior.gob.es/prensa/noticias/-/asset_publisher/ GHU8Ap6ztgsg/content/id/11676535

Policía Nacional (Ministerio del Interior). (2020). Guía para evitar ser manipulados por las fake news. [Cartel]. Recuperado de http://www. interior.gob.es/documents/10180/11579822/ INFOGRAF\%C3\%8DA.JPG/3ae014b4-9fa0-4eb88970-f99666d359a0?t=1585307278375

Roldán, D. (5 de abril de 2020). Más de 1,5 millones de cuentas falsas lanzan bulos en las redes sobre el COVID-19. El Correo Español-El Pueblo Vasco. [Reportaje]. Recuperado de www.elcorreo.com/ sociedad/salud/millones-cuentas-falsas-coronavirus20200405203007-ntrc.html

Sarráis, F. (2020). 30 Consejos para una vida feliz. Madrid, España: Palabra.

Velasco, J.M. (2020, 22 de abril). Desconfinamiento: El Gobierno vasco permitirá salir a correr y andar en bici... pero limitará los paseos. Marca. [Reportaje]. Recuperado de www.marca.com/tiramill as/2020/04/22/5ea0169eca4741063a8b45ea.html

Worldometer. (2020,22 deabril). COVID-19 coronavirus pandemic. [Base de datos]. Recuperado de www. worldometers.info/coronavirus 